\title{
Pengaruh Padatan Tersuspensi terhadap Konsentrasi Klorofil-a dan Fosfat Inorganik Terlarut di Muara Banjir Kanal Barat, Semarang
}

\author{
Jarot Marwoto, Oceana Windyartanti, Muslim* \\ Departemen Oseanografi, Fakultas Perikanan dan IImu Kelautan, Universitas Diponegoro \\ J. Prof. H. Soedarto, SH., Tembalang, Semarang, Jawa Tengah 50275 Indonesia \\ Email : aqua_muslim@yahoo.com
}

\section{Abstract \\ The Effect of Total Suspended Solids Distribution on Concentration of Chlorophyll-a and Dissolved Inorganic Phosphate at West Banjir Canal Estuary Semarang}

The large number of activities along the West Banjir Kanal river has triggered a change in the condition of its sea waters. The condition most affected is turbidity which caused high concentration of Total Suspended Solid (TSS) in estuary waters and interfere with the entry of sunlight into the waters. The purpose of the study is to determine the effect of the of concentration TSS on the concentration chlorophyll $a$ and dissolved inorganic phosphate (DIP) in the waters of West Banjir Kanal estuary. Water sampling was conducted on October 3, 2019. Water quality parameters such as brightness, $\mathrm{pH}$, temperature, DO and salinity were measured in situ. Meanwhile, chlorophyll a, TSS and DIP measurements were analyzed in the laboratory. The results showed that the highest concentration of TSS, chlorophyll a and DIP were in the estuary area and decreased with further distance from the river mouth with concentration were $70.17-151.50 \mathrm{mg} / \mathrm{L}, 0.03-2.67 \mu \mathrm{g} / \mathrm{L}$ and $0.71-0.98 \mu \mathrm{M}$ respectively. Based on the results of the Principal Component Analysis (PCA) showed that TSS affected chlorophyll $a$ by $8.7 \%(r=0.392 ; p<0.05)$ and DIP by $54.46 \%(r=0.931 ; p<0.01)$. The low regression between TSS and chlorophyll a was due to the presence of large amounts of inorganic particles in the West Banjir Kanal river, which makes the river waters become turbid. So, the turbidity of the waters caused the release of phosphate in the sediment to water column which was used by phytoplankton for photosynthesis, so the TSS not only contain sediment particles, but also phytoplankton.

Keywords : TSS, Chlorophyl-a, DIP, PCA, West Banjir Canal Estuary

\begin{abstract}
Abstrak
Banyaknya aktivitas di sepanjang sungai Banjir Kanal Barat Semarang, memicu kondisi perairan lautnya menjadi berubah. Kondisi yang paling terpengaruh adalah kekeruhan yang menyebabkan tingginya konsentrasi Material Padatan Tersuspensi (MPT) di perairan muara dan mengganggu masuknya cahaya matahari ke perairan. Penelitian ini bertujuan untuk mengetahui pengaruh MPT terhadap konsentrasi klorofil-a dan fosfat inorganik terlarut (DIP=Dissolved Inorganic Phosphate) di perairan Muara Banjir Kanal Barat Semarang. Pengambilan sampel air dilakukan pada tanggal 3 Oktober 2019. Parameter kualitas perairan seperti kecerahan, pH, suhu, DO dan salinitas diukur secara in situ. Sedangkan pengukuran klorofil-a, MPT dan DIP dianalisis di laboratorium. Hasil penelitian menunjukkan bahwa konsentrasi MPT, klorofil-a dan DIP tertinggi di daerah muara sungai dan menurun dengan makin jauhnya muara sungai dengan konsentrasi secara berturut-turut sebesar 70,17-151,50 mg/L, 0,03-2,67 $\mu \mathrm{g} / \mathrm{L}$ dan 0,71-0,98 $\mu \mathrm{M}$. Berdasarkan hasil Analisis Komponen Utama (AKU) menunjukkan bahwa MPT mempengaruhi klorofil-a sebesar 8,7\% $(r=0,392 ; P<0,05)$ dan fosfat inorganik terlarut sebesar $54,46 \%(r=0,931 ; P<0,01)$. Rendahnya hubungan antara MPT dengan klorofil-a ini disebabkan oleh adanya masukan partikel anorganik dalam jumlah besar di badan Sungai Banjir Kanal Barat yang membuat perairan sungai menjadi keruh. Jadi kekeruhan perairan menyebabkan terlepasnya fosfat di sedimen yang dimanfaatkan oleh fitoplankton untuk proses fotosintesa, sehingga yang terkandung dalam MPT selain partikel sedimen juga fitoplankton.
\end{abstract}

Kata kunci : MPT, Klorofil-a, DIP, AKU, Muara Banjir Kanal Barat 


\section{PENDAHULUAN}

Banjir Kanal barat yang lokasinya di tengah Kota Semarang sudah banyak dilakukan pembenahan. Banyak aktivitas industri dan rumah tangga yang dilakukan di sepanjang sungai. Tahun 2017 telah dibangun proyek bendung gerak dan telah selesai pada Desember 2019. Proyek ini menjadi salah satu proyek pembangunan yang beresiko tinggi karena memiliki dampak negatif terhadap lingkungan dan sosial ekonomi di sekitar proyek, walaupun mempunyai dampak positip sebagai pengendali banjir (Fatchiyati et al., 2019). Menurut Roehman (2019), salah satu dampak negatip adanya proyek ini terhadap lingkungan di Sungai Banjir Kanal Barat adalah berubahnya keseimbangan sedimen di sungai yang bisa mempengaruhi komponen biotik dan abiotik di perairan.

Partikel sedimen yang melayang dalam air dan bergerak tanpa menyentuh dasar perairan disebut dengan MPT (Material Padatan Tersuspensi). Besarnya nilai konsentrasi MPT dipengaruhi oleh adanya masukan dari aliran sungai (Paramitha et al., 2016), dan resuspensi sedimen, sehingga nilai MPT dapat mempengaruhi kecerahan. Resuspensi sedimen tersebut dipengaruhi oleh proses-proses hidrodinamika di laut seperti arus dan pasang surut (Handoyo et al., 2020). Tingginya MPT akan berpengaruh pada kurangnya cahaya matahari yang masuk ke perairan yang menyebabkan kurang optimumnya proses fotosintesis di perairan tersebut (Hartoko, 2010). Proses fotosintesis yang terganggu menyebabkan produktivitas primer perairan tersebut terganggu (Rasyid, 2010; Dewanto et al., 2015). Sumber MPT di muara perairan Banjir Kanal Barat banyak berasal dari beberapa aktivitas di sepanjang aliran sungai, seperti industri, rekreasi, dan pemukiman.

Proses produktivitas primer disamping sangat tergantung pada kecerahan juga diatur oleh ketersediaan nutrien di zona fotik perairan. Menurut Tyrell, (1999) dan Schenau et al., (2004) bahwa nutrient utama yang mengendalikan produktivitas primer di laut adalah fosfat. Tingginya produktivitas primer yang ditunjukkan dengan nilai klorofil-a nya di suatu perairan estuarin dapat juga meningkatkan MPT karena justru yang menyusun MPT adalah fitoplankton (Muslim \& Jones, 2003).

Berdasarkan fenomena tersebut, maka perlu dilakukan penelitian dengan tujuan untuk mengetahui pengaruh sebaran konsentrasi MPT terhadap konsentrasi klorofila, dan fosfat anorganik terlarut (DIP: Dissolved Inorganic Phosphate) di perairan muara Sungai Banjir Kanal Barat Kota Semarang. Pada penelitian ini, pengambilan data lapangan dibatasi pada kondisi perairan dalam keadaan pasang menuju surut dan pada periode musim peralihan kedua.

\section{MATERI DAN METODE}

Materi yang digunakan dalam penelitian ini adalah sampel air perairan Muara Banjir Kanal Barat Semarang yang diambil pada tanggal 3 Oktober 2019. Data primer yang digunakan meliputi data hasil pengukuran langsung pada saat pengambilan sampel air berupa data kualitas perairan (suhu, kecerahan, DO, pH, dan salinitas) dan data yang dianalisa di Laboratorium berupa data MPT, klorofil-a dan fosfat inorganik terlarut (DIP). Sedangkan data sekunder berupa Peta Batimetri Digital Semarang (BATNAS), dan Peta Rupa Bumi Indonesia (BIG).

Lokasi penelitian berada di muara Sungai Banjir Kanal Barat yang secara geografis terletak pada -6 ${ }^{\circ} 55^{\prime} 30^{\prime \prime}$ LS sampai $6^{\circ} 57^{\prime} 00^{\prime \prime} \mathrm{LS}$ dan $110^{\circ} 22^{\prime} 30^{\prime \prime}$ BT sampai $110^{\circ} 24^{\prime} 30^{\prime \prime}$ BT. Pengambilan sampel dilakukan pada 9 stasiun pengamatan dengan pembagian 3 zona. Zona I (Stasiun 1, 2 dan 3) mewakili muara sungai, zona II (Stasiun 4, 5 dan 6) mewakili daerah transisi antara depan muara dan laut, dan zona III (stasiun 7, 8 dan 9) mewakili laut lepas.

Sampel air laut diambil pada saat kondisi perairan dalam keadaan pasang menuju surut dengan menggunakan water sampler pada kedalaman $20 \mathrm{~cm}$ dari permukaan air. Sampel air laut tersebut dimasukkan ke botol sampel dengan volume $1000 \mathrm{ml}$ yang telah dibilas dua kali dengan sampel air. Selanjutnya botol sampel yang telah berisi sampel air laut disimpan dalam 
cool box yang berisikan batu es dan langsung dibawa ke laboratorium untuk dianalisis kandungan MPT, klorofil-a dan fosfat inorganik terlarut (DIP).

Penentuan residu tersuspensi atau MPT dilakukan dengan menggunakan metode Gravimetri (SNI 06-6989.27-2005). Penentuan konsentrasi klorofil-a dilakukan menggunakan metode spektrofotometri dengan spektrofotometer UV-Vis (Parson et al., 1989; Riyono, 2006) dengan rumus :

$$
\begin{gathered}
\text { Klorofil } a= \\
\frac{[(11.85 \times \lambda 664)-(1.54 \times \lambda 647)-(0.08 \times \lambda 630)] \times V e}{V s \times d}
\end{gathered}
$$

Keterangan: $\lambda 664=$ Abs $664 \mathrm{~nm}-$ Abs $750 \mathrm{~nm}$; $\lambda 647=$ Abs $647 \mathrm{~nm}-$ Abs $750 \mathrm{~nm} ; \lambda 630=$ Abs $630 \mathrm{~nm}$ - Abs $750 \mathrm{~nm}$; d = Lebar diameter kuvet $(1 \mathrm{~cm}) ; \mathrm{Ve} \quad=$ Volume ekstrak aceton $(\mathrm{mL})$; $V_{s}=$ Volume sampe air sampel yang disaring (L).

Nutrien fosfat inorganik terlarut (DIP) diukur dengan menggunakan metode colorimetric dengan bantuan spektrofotometer UV-Vis. Metode ini membandingkan warna larutan sampel dengan warna larutan standar yang diserikan. Setiap senyawa kimia akan memiliki warna yang spesifik karena reagent yang ditambahkan juga spesifik, begitu pula dengan panjang gelombang yang digunakan juga spesifik (Muslim, 2012). Reagent yang digunakan untuk pengukuran fosfat inorganik terlarut yaitu asam sulfat, asam askorbit, potassium antimonil tartat dan ammonium heptamolybdate. Larutan yang sudah ditambahkan dengan reagent tersebut setelah ditunggu sekitar 20-30 menit akan tampak berwarna kebiruan, dimana kekuatan warnanya tergantung pada besarnya konsentrasi fosfat inorganik terlarut. Panjang gelombang yang dipilih adalah $885 \mathrm{~nm}$.

\section{Analisis Komponen Utama (AKU)}

Analisis ini untuk melihat variabel mana dalam kumpulan data yang terukur yang merupakan variabel utama yang saling mempengaruhi. Menurut Van Delsen et al. (2017) Analisis Komponen Utama (AKU) ini didasarkan pada matriks korelasi yang digunakan untuk mendapatkan nilai kedekatan hubungan antar variabel penelitian. Keterkaitan hubungan ini diperoleh dari :

\section{Uji Barlett}

Uji ini digunakan untuk mengetahui kuatnya korelasi dari hasil uji dengan SPSS,

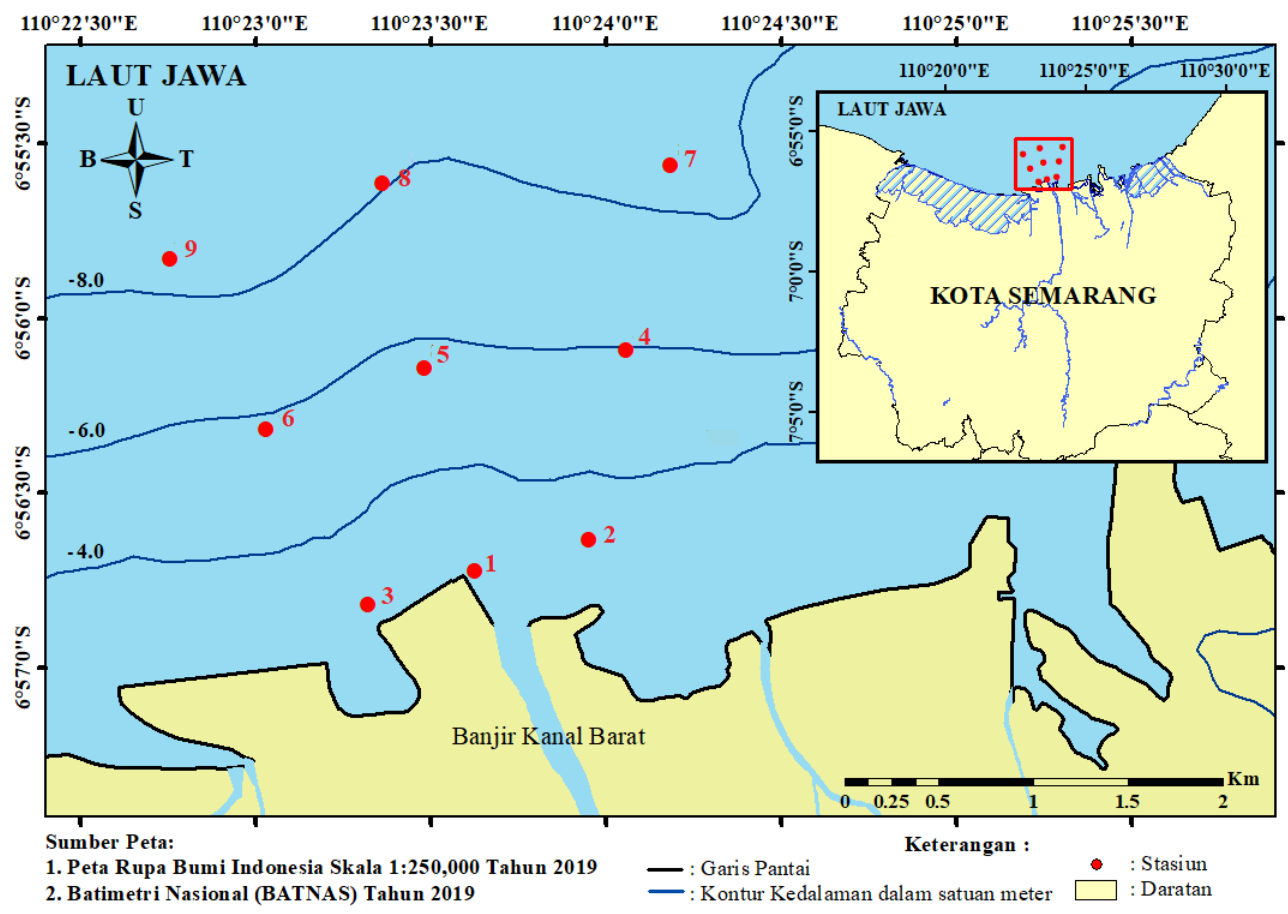

Gambar 1. Stasiun Pengambilan Sampel. 
dimana korelasi akan digunakan apbila nilainya kurang dari 0,05. (Hadi, et al., 2016)

$$
x_{o b s}^{2}=-\left[(N-1)-\frac{(2 p+5)}{6}\right] \ln |R|
$$

Keterangan : $N=$ jumlah observasi; $p=$ jumlah variabel; $|R|$ = determinan matriks korelasi

\section{Uji Kaiser Meyer Olkin (KMO)}

Uji ini digunakan untuk mengukur kecukupan sampelnya yang merupakan syarat untuk AKU (Supranto, 2004).

$$
\begin{aligned}
K M O=\frac{\sum_{i \neq j} r_{i j}^{2}}{\sum \sum_{i \neq j} r_{i j}^{2}+\sum \sum_{i \neq j} a_{i j}^{2}}, i \\
=1,2, \ldots, p ; j=1,2, \ldots, p
\end{aligned}
$$

Keterangan: $r_{i j}=$ koefisien korelasi sederhana antara variabel ke-i dan ke-j; $a_{i j}=$ koefisien korelasi parsial antara variabel ke-i dan ke-j

\section{Korelasi Pearson}

uji korelasi Pearson Product Moment untuk mengetahui derajat keterkaitan hubungan dan arah hubungan antar variabel. Analisis ini menggunakan software IBM SPSS Statistic 26. Keterkaitan hubungan antara variabel satu dengan variabel lainnya dapat diketahui dengan menggunakan Pearson correlation (Riduwan, 2009).

$$
r=\frac{n \sum x y-\left(\sum x\right)\left(\sum y\right)}{\sqrt{\left[n \sum x^{2}-\left(\sum x\right)^{2}\right]\left[n \sum y^{2}-\left(\sum y\right)^{2}\right]}}
$$

Keterangan: $r=$ korelasi antara $x$ dengan $y$; $\mathrm{x}=$ nilai $\mathrm{x} ; \mathrm{y}=$ nilai $\mathrm{y} ; \mathrm{n}=$ banyaknya nilai

\section{HASIL DAN PEMBAHASAN}

Persebaran parsial konsentrasi MPT, Klorofil-a dan DIP ditampilkan dalam Gambar 2, 3 dan 4 dan Tabel 1, dimana terlihat bahwa konsentrasi ketiga parameter tersebut menunjukkan penurunan konsentrasi dengan menjauhnya dari muara sungai. Konsentrasi tertinggi terjadi pada daerah zona 1 yang mewakili muara sungai dan konsentrasi terendah terjadi di daerah zona 3 yang mewakli daerah menuju lepas pantai. Sebaran konsentrasi MPT terlihat konsentrasi tertinggi berada di stasiun 3 sebesar 151,50 $\mathrm{mg} / \mathrm{L}$ dan terendah berada di stasiun 9 sebesar 70,16 mg/L dengan rata-rata sebesar 103,47mg/L (Gambar 2). Konsentrasi klorofil-a tertinggi berada di stasiun 1 sebesar $2,67 \mu \mathrm{g} / \mathrm{L}$ dan terendah berada di stasiun 9 sebesar 0,03 $\mu \mathrm{g} / \mathrm{L}$ dengan rata-rata sebesar $1,36 \mu \mathrm{g} / \mathrm{L}$ (Gambar 3). Konsentrasi DIP tertinggi berada di stasiun 3 sebesar $0,98 \mu \mathrm{M}$ dan terendah berada di stasiun 9 sebesar $0,72 \mu \mathrm{M}$ dengan rata-rata sebesar 0,78 $\mu \mathrm{M}$ (Gambar 4).

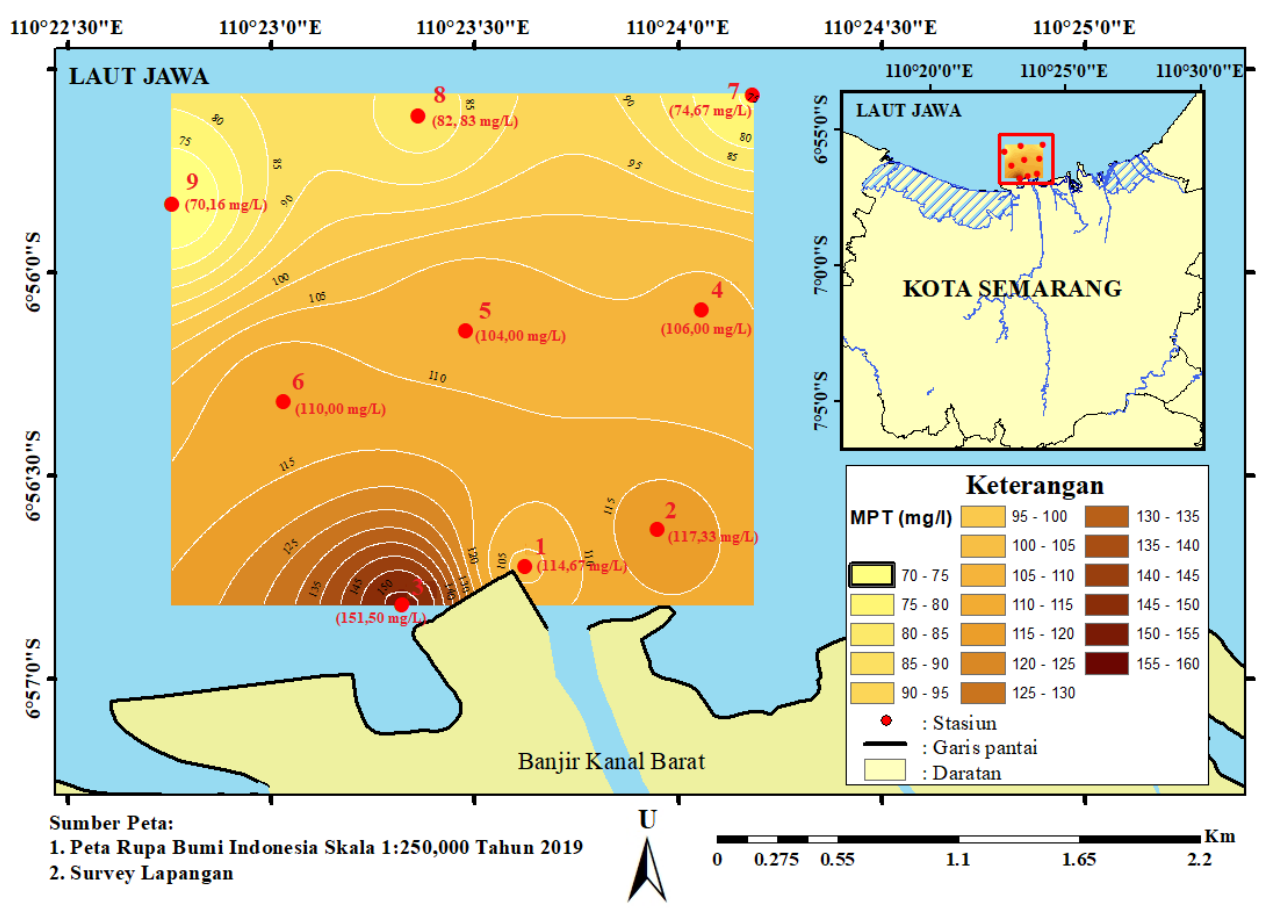

Gambar 2. Persebaran MPT (mg/L). di Muara Banjir Kanal Barat Semarang 


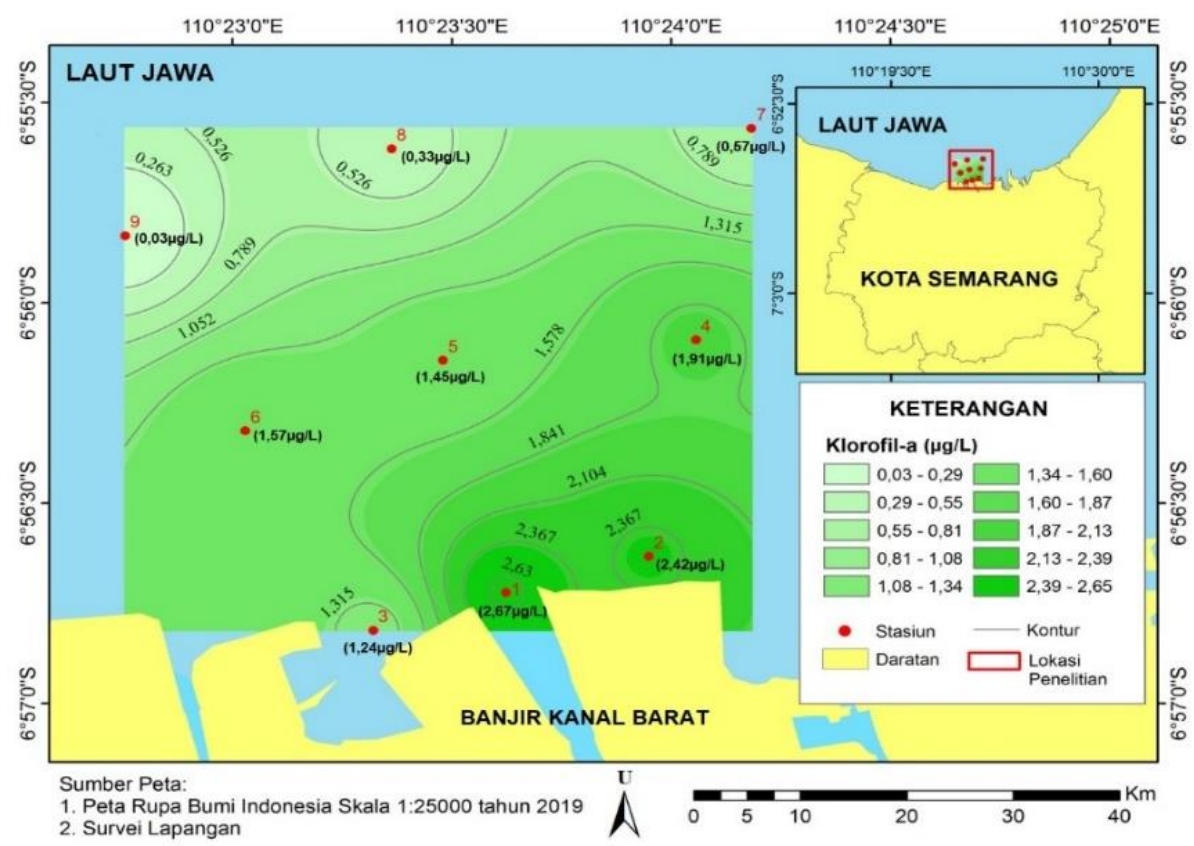

Gambar 3. Persebaran Klorofil-a ( $\mu \mathrm{g} / \mathrm{L})$.di Muara Banjir Kanal Barat

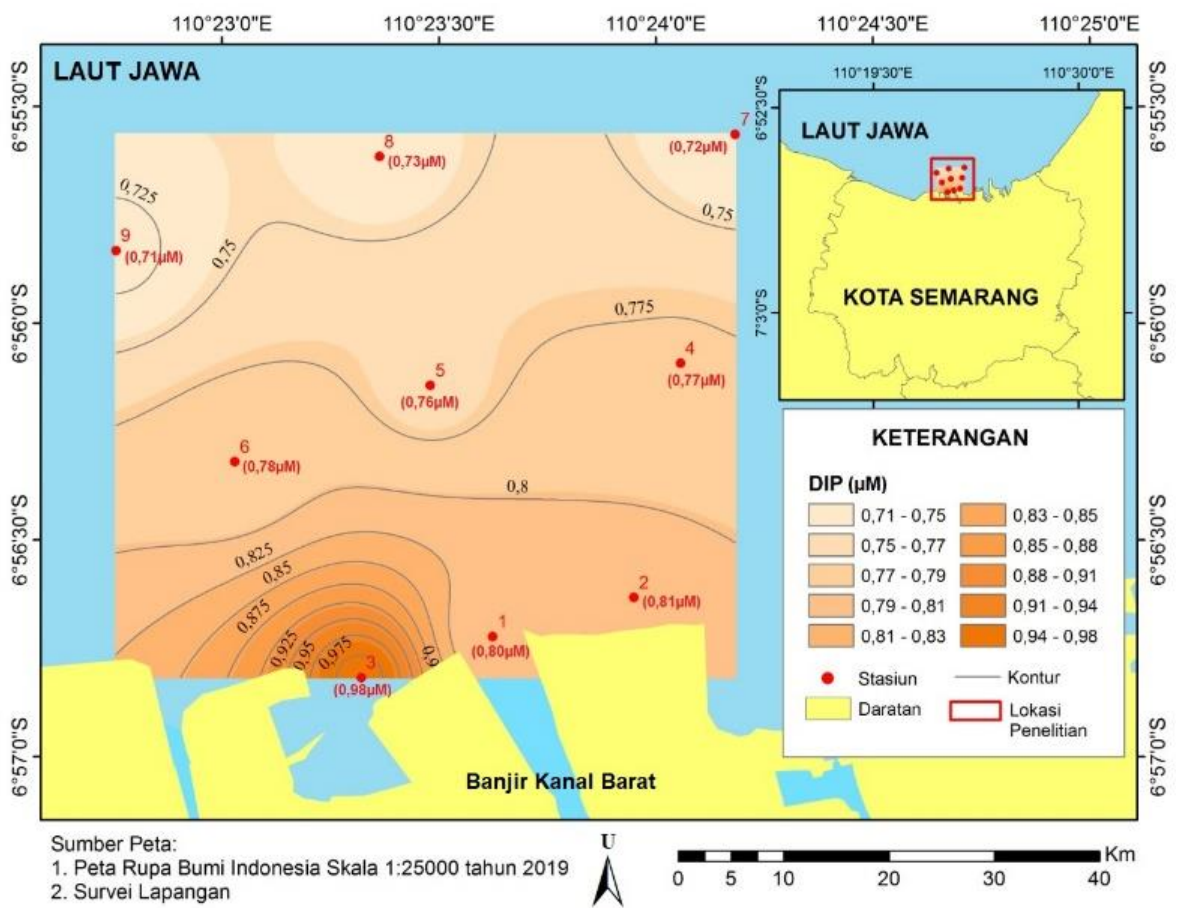

Gambar 4. Persebaran DIP ( $\mu M)$. di Muara Banjir Kanal Barat

Hasil pengukuran parameter kualitas perairan yang melitputi suhu, kecerahan, DO, $\mathrm{pH}$, dan salinitas secara keseluruhan disajikan dalam Tabel 1. Kondisi perairan pada saat pengambilan sampel air laut terlihat di semua stasiun menunjukkan sedikit basa dengan $\mathrm{pH}$
7,28-7,84 dengan rata-rata 7,49. Temperatur terdeteksi dari $30,2-30,9{ }^{\circ} \mathrm{C}$ dengan nilai ratarata $30,5{ }^{\circ} \mathrm{C}$. Oksigen terlarut (DO) untuk daerah zona I (muara sungai) menunjukkan nilai 5,83-7,30 $\mathrm{mg} / \mathrm{L}$ yang jauh lebih rendah dari zona II dan III dengan konsentrasi 8,30- 
$9,20 \mathrm{mg} / \mathrm{L}$. Adapun salinitasnya nilainya 25-34 \%o dengan nilai rata-rata $31,88 \%$.

Hasil perhitungan pasang surut menggunakan admiralty didapatkan bahwa tipe pasang surut di saat pengambilan sampel adalah tipe campuran condong ke ganda (mixed tide prevailing semi diurnal) dengan nilai formhzal sebesar 0,73. Hasil Analisis Komponen Utama (AKU) disajikan dalam uji KMO (Kaiser-Meyer-Olkin) dan Bartlett (Tabel 2), korelasi pearson (Tabel 3) dan correlation circle (Gambar 5). Hasil Uji KMO (Tabel 2) diperoleh nilai 0,552 yang menunjukkan bahwa data yang digunakan cukup baik untuk diteliti. Sedangkan pada hasil Uji Bartlett diperoleh nilai 77,516 dengan signifikansi sebesar 0,0001. Hal tersebut menunjukkan hasil dari Uji Bartlett tersebut memenuhi syarat karena nilai signifikansinya di bawah 0,05. Hasil korelasi Pearson (Tabel 3) terlihat bahwa MPT mempunyai hubungan yang signifikan dengan klorofil a $(P<0,05)$ dan DIP $(P<0,01)$.

Persebaran konsentrasi MPT terlihat sangat ditentukan oleh sumbernya, dimana konsentrasi tertinggi terjadi di zona I (muara sungai) tepatnya di stasiun 3 (Gambar 2) yang merupakan zona yang paling dekat dengan sungai sebagai sumber MPT, juga karena saat pengambilan sampel pada saat pasang menuju surut yang menyebabkan gelombang yang sampai di daerah muara cukup besar sehingga menyebabkan pengadukan sedimen di dasar perairan dan terjadi resuspensi partikel sedimen di muara. Menurut Triatmodjo (1999) bahwa energi transport pada saat pasang lebih besar daripada saat

Tabel 1. Konsentrasi MPT, Klorofil-a, DIP dan Kualitas Perairan.

\begin{tabular}{ccccccccc}
\hline Stasiun & $\begin{array}{c}\text { MPT } \\
(\mathrm{mg} / \mathrm{L})\end{array}$ & $\begin{array}{c}\text { Klorofil-a } \\
(\mu \mathrm{g} / \mathrm{L})\end{array}$ & $\begin{array}{c}\mathrm{DIP} \\
(\mu \mathrm{M})\end{array}$ & $\begin{array}{c}\text { Kecerahan } \\
(\mathrm{m})\end{array}$ & $\begin{array}{c}\text { Salinitas } \\
(\% \circ)\end{array}$ & $\mathrm{pH}$ & $\begin{array}{c}\text { Suhu } \\
\left({ }^{\circ} \mathrm{C}\right)\end{array}$ & $\begin{array}{c}\mathrm{DO} \\
(\mathrm{mg} / \mathrm{L})\end{array}$ \\
\hline 1 & 114,67 & 2,67 & 0,80 & 0,6 & 25 & 7,28 & 30,7 & 7,13 \\
2 & 117,33 & 2,42 & 0,81 & 0,5 & 30 & 7,32 & 30,6 & 7,30 \\
3 & 151,50 & 1,24 & 0,98 & 0,4 & 32 & 7,35 & 30,9 & 5,83 \\
4 & 106,00 & 1,91 & 0,77 & 0,7 & 33 & 7,36 & 30,3 & 8,90 \\
5 & 104,00 & 1,45 & 0,76 & 0,8 & 33 & 7,50 & 30,7 & 9,13 \\
6 & 110,00 & 1,57 & 0,78 & 0,6 & 33 & 7,52 & 30,5 & 8,17 \\
7 & 74,67 & 0,57 & 0,72 & 1,2 & 33 & 7,84 & 30,2 & 8,67 \\
8 & 82,83 & 0,33 & 0,73 & 1,0 & 34 & 7,62 & 30,4 & 9,20 \\
9 & 70,17 & 0,03 & 0,72 & 1,2 & 34 & 7,69 & 30,2 & 8,30 \\
\hline Rerata & 103,47 & 1,36 & 0,78 & 0,77 & 31,88 & 7,49 & 30,5 & 8,07 \\
\hline
\end{tabular}

Tabel 2. Uji KMO dan Bartlett

\begin{tabular}{llr}
\hline Kaiser-Meyer-Olkin Measure of Sampling Adequacy &, 552 \\
\hline Bartlett Test of & Chi-Square (Observed value) & 77,516 \\
Sphericity & Chi-Square (Critical value) & 41,337 \\
& Df & 28 \\
& Sig. / p-value (Two-tailed) & $<, 0001$ \\
& Alpha & 0,05 \\
\hline
\end{tabular}

Tabel 3. Korelasi Pearson antara MPT, klorofil-a, DIP dengan parameter kualitas air

\begin{tabular}{|c|c|c|c|c|c|c|c|c|}
\hline $\mathrm{R}$ & MPT & Klorofil-a & DIP & Kecerahan & Salinitas & $\mathrm{pH}$ & Suhu & DO \\
\hline MPT & & $0,392^{b}$ & $0,931 \mathrm{a}$ & $-0,948 a$ & $-0,408$ & $-0,811 \mathrm{a}$ & $0,877 a$ & $-0,359$ \\
\hline Klorofil-a & & & 0,185 & $-0,526$ & $-0,973 a$ & $-0,691$ & 0,427 & $-0,217$ \\
\hline DIP & & & & $-0,783^{b}$ & $-0,266$ & $-0,616$ & $0,799 a$ & $-0,397$ \\
\hline
\end{tabular}

a Korelasi Pearson signifikan pada $\mathrm{P}<0,01$

b Korelasi Pearson signifikan pada $\mathrm{P}<0,05$ 


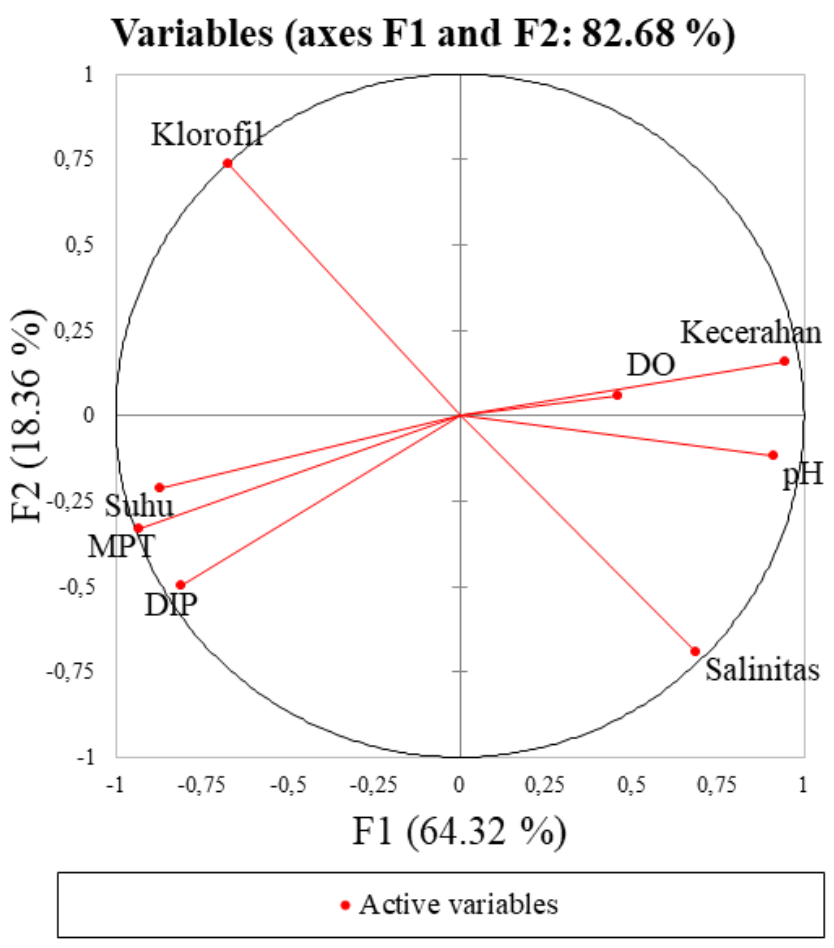

Gambar 5. Correlation Circle

surut, sehingga daya resuspensi saat pasang lebih besar. Selanjutnya konsentrasi MPT menurun dengan menjauhnya dari muara sungai dan konsentrasi terendah terjadi pada stasiun 9 yaitu sebesar 70,17 mg/L, hal ini disamping karena sebaran MPT dari sumbernya sudah tinggal sedikit sampai di stasiun 9, juga karena pengadukan disebabkan arus kurang mampu mengaduk sedimen dasar naik ke permukaan.

Hasil uji Korelasi Pearson (Tabel 3 dan Gambar 5) terlihat bahwa MPT mempunyai hubungan positip yang signifikan dengan klorofil-a $(P<0,05)$ dan DIP $(P<0,01)$, artinya bahwa meningkatnya MPT menyebabkan meningkatkan klorofil-a, karena yang terkandung dalam MPT didominasi oleh fitoplankton, hal ini sama yang terjadi di Great Barrier Reef Australia bahwa pada saat blooming fitoplankton Trychodesmium mempengaruhi meningkatnya MPT (Muslim \& Jones, 2003). Hal ini karena bersamaan dengan meningkatnya MPT juga meningkatkan DIP yang mendorong tumbuhnya fitoplankton, karena saat terjadi resuspensi sedimen, senyawa yang ada di sedimen termasuk nutrient dilepaskan ke perairan sebagai secondary resources nutrien (Muslim et al., 2015; Ahmed et al., 2021) untuk proses fotosintesis. Proses ini sama pada kejadian di laut lepas, dimana meningkatkan klorofil-a terjadi saat kandungan DIP-nya meningkat sebagai akibat pengadukan atau upwelling (Ghaemi, et al., 2021).

Berdasarkan hubungan yang signifikan antara klorofil-a dan DIP (Tabel 3), menyebabkan kedua parameter tersebut menyebar seirama, dimana pada daerah zona I (muara sungai) konsentrasinya MPT dan DIP menunjukkan nilai yang paling tinggi dan selanjutnya menurun dengan semakin jauhnya dari muara sungai sebagai sumbernya (Gambar 2 dan 4). Fenomena meningkatnya produktivitas primer (fitoplankton) dalam suatu perairan yang dipengaruhi oleh nutrien yang berperan, sangat penting dalam menentukan limiting faktornya (Lundsør et al., 2020). Hal ini juga sangat penting untuk mengantisipasi terjadinya over produksi fitoplankton (blooming) yang dapat menurunkan kualitas perairan (Nixon, 1995), karena biomas 
plankton yang tenggelam akan mengkonsumsi oksigen di dasar perairan (Staalstrøm, 2015). Yang lebih membahayakan lagi apabila yang berkembang adalah alga yang beracun (Heisler et al., 2008).

Ditinjau dari kondisi parameter kualitas airnya yang meliputi kecerahan, salinitas, $\mathrm{pH}$, suhu dan DO terlihat mempunyai nilai yang normal dengan nilai rerata secara berturutturut $0,77 \mathrm{~m}, 31,88 \%$ o, $7,49,30,5^{\circ} \mathrm{C}$ dan 8,07 $\mathrm{mg} / \mathrm{L}$ (Tabel 1). Beberapa parameter tersebut ada yang mempunyai hubungan korelasi secara signifikan baik secara negatip maupun positip (Tabel 3). Hubungan tersebut bersifat spasial, artinya bahwa terjadinya hubungan hanya pada kondisi, tempat dan wakktu tertentu (Kim et al., 2021) dan oleh Muslim et al., (2017) dikatakan hubungannya bersifat relatip, karena banyak ditentukan oleh kondisi limbah buangan dari sungai terutama bahan organik dan air tawar.

\section{KESIMPULAN}

Berdasarkan uraian tersebut di atas dan hasil uji statistik dapat disimpulkan bahwa konsentrasi MPT di perairan muara Banjir Kanal Barat berpengaruh positif terhadap konsentrasi klorofil-a $(r=0,392 ; P<0,05)$ dan fosfat inorganik terlarut/DIP $(r=0,931 ; P<0,01)$. Aktifitas di sekitar sungai Banjir Kanal Barat tidak menurunkan kualitas perairan dan beberapa parameter mempunyai korelasi positip dan negatip yang signifikan terhadap MPT, Klorofil-a dan DIP yang bersifat spasial atau relatip.

\section{DAFTAR PUSTAKA}

Ahmed, W., Wu, Y., Kidwai, S., Li, X., Zhang, G., and Zhang, J. 2021. Spatial and Temporal Variations of Nutrients and Chlorophyll a in the Indus River and Its Deltaic Creeks and Coastal Waters (Northwest Indian Ocean, Pakistan). Journal of Marine Systems, 218: p103525, 1-16p, doi : 10.1016/j.jmarsys.20 21.103525

Dewanto, W., Ismanto, A., \& Widianingsih. 2015. Analisis Sebaran Horizontal Klorofil-a di Perairan Tugu Semarang. Jurnal Oseanografi. 4(2):366-378.

Fatchiyati, A., Rachmawati, D., \& Anggraini, L. 2019. Analisis Manajemen Resiko
Pembangunan Bendung Gerak Banjir Kanal Barat Kota Semarang dan Dampaknya Terhadap Lingkungan. Jurnal Teknika Universitas Semarang. 14(1): $30-40$.

Ghaemi, M., Abtahi, B., \& Gholamipour, S. 2021. Spatial Distribution of Nutrients and Chlorophyll A Across the Persian Gulf and the Gulf of Oman. Ocean and Coastal Management, 201:p105476, 1-10p doi: 10.1016/j.ocecoaman.2020.105476

Hadi, N.U., Abdullah, N \& Sentosa, I. 2016. An Easy Approach to Exploratory Factor Analysis: Marketing Perspective. Journal of Educational and Social Research 6(1): 215-223, DOI: 10.5901/jesr.2016.v6n1p215

Handoyo, G., Subardjo, P., Kusumadewi, V., Rochaddi, B., \& Widada S. 2020. Pengaruh Pasang Surut Terhadap Sebaran Material Padatan Tersuspensi di Pantai Dasun Kabupaten Rembang. Indonesian Journal of Oceanography. 2(1):16-23.

Hartoko, A. 2010. Oseanografi dan Sumber Daya Perikanan Kelautan di Indonesia. Undip Press, Semarang. $466 \mathrm{hlm}$

Heisler, J., Glibert, P.M., Burkholder, J.M., Anderson, D.M., Cochlan, W., Dennison, W.C., Dortch, Q., Gobler, C.J., Heil C.A., Humphries, E., Lewitus, A., Magnien, R., Marshall, H.G., Sellner, K., Stockwell, D.A., Stoecker, D.K., \& Suddleson, M. 2008. Eutrophication and Harmful Algal Blooms: A Scientific Consensus. Harmful Algae 8: 3-13. doi: 10.1016/j.hal.2008.08.006.

Kim, H.G., Hong, S., Chon, T.S., \& Joo, G.J. 2021. Spatial Patterning of Chlorophyll A and Water-Quality Measurements for Determining Environmental Thresholds for Local Eutrophication in the Nakdong River Basin. Environmental Pollution, 268: p1 15701, doi: 10.1016/j.envpol.2020.115701

Lundsør, E., Stigea, L.C., Sørensenc, K., \& Edvardsena, B. 2020. Long-Term Coastal Monitoring Data Show Nutrient-Driven Reduction in Chlorophyll. Journal of Sea Research, 164:p101925. doi: 10.1016/j.sea res.2020.101925

Muslim, \& Jones, G. 2003. The Seasonal Variation of Dissolved Nutrients, Chlorophyll a and Suspended Sediment at Nelly Bay, Magnetic Island. Estuarine, Coastal and Shelf Science. 57:445-455. doi: 10.1016/S0272-7714(02)00373-6 
Muslim. 2012. UV-VIS Spektrofotometer : Teori, Konsep, dan Penggunaannya untuk Analisa Kimia Laut. Unnes Press, Semarang. $133 \mathrm{hlm}$.

Muslim., Suseno, H., \& Rafsani, F. 2015. Distribution of ${ }^{137} \mathrm{Cs}$ Radionuclide in Industrial Wastes Effluents of Gresik, East Java, Indonesia. Atom Indonesia, 41 (1):47 -50. doi: 10.17146/aij.2015.355

Muslim., Prihatiningsih, W.R., \& Nugroho, A.B. 2017. Relative Effect of Water Quality on ${ }^{137} \mathrm{Cs}$ Activity in Larangan Water, Tegal. Jurnal Sains Nuklear Malaysia. 29(1):45-61

Nixon, S.W., 1995. Coastal and Marine Eutrophication: A Definition, Social Causes and Future Concerns. Ophelia 41:199-219.

Paramitha, V.K., Yusuf, M., \& Maslukah, L. 2016. Sebaran Muatan Padatan Tersuspensi (MPT) di Perairan Karangsong, Kabupaten Indramayu. Jurnal Oseanografi. 5(2):293 300.

Parson, T.R., Maita, Y., \& Lalli, C.M. 1989. A Manual of Chemical and Biological Methods for Seawater Analysis. Pergamon Press, New York. 173p.

Rasyid, A. 2009. Distribusi Klorofil-a Pada Musim Peralihan Barat-Timur di Perairan Spermonde Propinsi Sulawesi Selatan. Jurnal Sains dan Teknologi .9(2):125 - 132.

Riduwan. 2009. Dasar-Dasar Statistika. Bandung: Alfabeta, $273 \mathrm{hlm}$.
Riyono, S.H. 2006. Beberapa Metode Pengukuran Klorofil Fitoplankton di Laut. Jurnal Oseana. 31 (3):33-44.

Roehman, F. 2019. Rencana Strategi Bendung Karet Berisi Air Sebagai Inovasi Tepat Guna Dalam Penanggulangan Banjir dan Rob. Jurnal Neo Teknika. 5(1):8-14.

Schenau, S.J., Richart, G.J., \& De Lange, G.J. 2004. Phosphorus Burial as A Function of Paleoproductivity and Redox Condition in Arabian Sea Sediment. Geochima et Cosmochimica Acta. 69(4):919-931.

SNI 06-6989.27-2005. Air dan Air limbah Bagian 27 : Cara Uji Kadar Padatan Terlarut Total secara Gravimetri. ICS 13.060.01.

Staalstrøm, A., 2015. Tidally-Induced Turbulent Mixing in a Sill Fjord. University of Oslo.

Supranto, J. 2004. Analisis Multivariat: Arti \& Interpretasi, Jakarta : Rineka Cipta. 359 $\mathrm{hlm}$

Triatmodjo, B. 1999. Teknik Pantai. Beta Offset, Yogyakarta. 397hlm.

Tyrell, T. 1999. The Relative Influence of Nitrogen and Phosphorus on Oceanic Primary Production. Nature. 400: 525 - 531.

Van Delsen, M.S.N., Wattimena, A.Z., \& Saputri, S.D. 2017. Penggunaan Metode Analisis Komponen Utama Untuk Mereduksi Faktor-Faktor Inflasi di Kota Ambon. Barekeng : Jurnal IImu Matematika dan Terapan. 11 (2):109-118. 